\title{
Lessons learnt from the use of relationship-based procurement methods in Australia: clients' perspectives
}

\author{
Farshid Rahmani, Malik M A Khalfan and Tayyab Maqsood \\ School of Property, Construction and Project Management, RMIT University, Australia
}

\begin{abstract}
This paper aims to review the use of various construction procurement systems and present the development of Relationship-Based Procurement (RBP) Methods currently in use within the Australian construction industry. Therefore, this paper provides the historical development of procurement briefly and then focuses on the adoption of Relationship-Based Procurement (RBP) approaches in the Australian construction industry to investigate the future direction of the collaborative project procurement arrangements. Semi-structured interviews with high-level managers in the Australian state government organizations have been conducted to answer the research question. A discussion has been presented about the potential future tendency of the industry in adopting a RBP. The findings suggest that even though relationship based procurement systems offer significant benefits; they are not popular among the public sector decision makers because of inability to demonstrate Value for Money (VfM) propositions for public projects. Other reasons which may cause a move away from using RBPs in the future include the need for managers to fully engage throughout the project, and the lack of collaborative environment within the construction industry in general.
\end{abstract}

Keywords: Procurement routes, Australia, Relationship-Based Procurement (RBP), construction clients.

Paper type: Research article

\section{Introduction}

Procurement method is used to describe a variety of ways such as functions, organisations, resources, systems, processes and strategies (McDermott, 1999; Rowlinson and McDermott, 1999; Palaneeswaran, Kumaraswamy and Ng, 2003; Nissen, 2009; Love et al., 2012). The definition of procurement within construction has also evolved in last few decades. Mohsini and Davidson (1989, p.86) defined procurement initially as 'the acquisition of new buildings, or space within buildings, either by directly buying, renting, or leasing from the open market, or by designing and building the facility to meet a specific need'. This was refined after one decade as 'a strategy to satisfy the client's development and/or operational needs with respect to the provision of constructed facilities or a discrete life cycle' (Lenard and Mohsini 1998, p.79). Nissen (2009, p.247) explains that 'procurement was once descriptive of the simple clerical activities associated with purchasing well-specified items, but it has evolved in some organizations to describe instead strategic partnering efforts made by senior executives'. The importance of using a right procurement method for a project, hence, cannot be overemphasized and has caused a proliferation of studies in this field in recent years (Love, Smith and Regan

Copyright: Construction Economics and Building 2016. (C) 2016 Farshid Rahmani, Malik Khalfan and Tayyab Maqsood. This is an Open Access article distributed under the terms of the Creative Commons Attribution 4.0 Unported (CC BY 4.0) License (https://creativecommons.org/licenses/by/4.0/), allowing third parties to copy and redistribute the material in any medium or format and to remix, transform, and build upon the material for any purpose, even commercially, provided the original work is properly cited and states its license.

Citation: Rahmani, F., Khalfan, M.M.A. and Maqsood, T. 2016. Lessons learnt from the use of relationship-based procurement methods in Australia: clients' perspectives, Construction Economics and Building, 16(2), 1-13. DOI: http://dx.doi.org/10.5130/AJCEB.v16i2.4634 
2010a; Love, Smith and Regan 2010b; Love et al. 2008; Love, Skitmore and Earl 1998; Masterman 2002; Miller et al. 2009; Skitmore and Marsden 1988).

This paper aims to explore the present outlook of the clients for the adoption of emerging procurement methods in the future. The study focused on the public organizations in the Australian construction industry. Influenced by the aim of this study, the main question is:

What is the perception of the clients towards the emerging procurements methods and what is envisaged for the future?

This paper begins with a review of the salient literature on the procurement management domain to provide an overview of the new generation of procurement systems referred to as relationship-based procurement methods (RBP) which are relied on for partnering and collaborative relationships. The paper then reports the findings of the study about the construction client's perception of the future trend of the RBP adoption in Australia.

\section{Literature review}

The construction industry is frequently described as being dominated by a 'culture of confrontation' in which a vicious cycle of mistrust, conflict and waste dominates (Seymour and Fellows 1999), and has attracted a great deal of criticism in recent years for its inability to meet the needs of its clients. Many articles within academic and professional construction journals have identified problems such as cost and program overruns, poor quality and performance, low profitability, onerous contract conditions, and a multitude of disputes. The industry has been characterized by adversarial attitudes, with litigation often continuing long after projects have finished. Seminal reports by Latham (1994) and Egan (1998) in the UK, both identified a pressing need for change. Subsequently, the construction industry has embarked on a sustained campaign to overcome its perceived performance problems through a number of initiatives and radically different approaches to the procurement and management of construction projects. Relationship-based procurement routes represent perhaps the most significant development to date as a means of improving project performance, whilst offering direct benefits to the whole supply chain. These new delivery systems aim to achieve specific business objectives by maximizing the effectiveness of each participant's resources and establishing ongoing business relationships (Wood 2005).

Partnering, probably the most popular term used to describe the collaborative approach, suggests that the project success is likely to occur when all of the parties involved work together for the good of the project rather than for the good of themselves independently (Morledge, Smith and Kashiwagi, 2006) and seen by many to be a necessary new approach to managing what is often an unpredictable process with the traditional approaches (Hinks et al. 1996; McDermott and Khalfan, 2006). A robust characterization is provided by Stevens (1993) that partnering is recognition that every contract includes an agreement of good faith but partnering is not a contract itself. Rather, it refers to working relationships between the parties that are developed based on trust, dedication to common goals, and an understanding of the expectations and values of each participant (Contruction Industry Institute, 1991). Partnering, therefore, can exist within a wide range of procurement methods; from traditional competitive design, bid and build for single project, to long-term commitments formed to respond to the total engineering, procurement, and construction needs of an owner (Thompson and Sanders, 1998). Partnering aims to establish working relationships between stakeholders through a formal strategy of commitment and communication that is mutually developed. It attempts to create an environment where trust and teamwork prevent disputes, foster a co-operative bond to everyone's benefit, and facilitate the completion of a successful project. Hinks et al (1996) also define partnering as a structured management approach to facilitate team working across 
contractual boundaries, aiming to obtain specific business objectives by improving the efficiency and effectiveness of each party's resources and building continuous business rapport.

Even though the need for high-level commitment is essential, there is also a need for internal readiness assessment to take place within an organization prior to commitment to enter into a partnering agreement. This means preparing the organization and reviewing internal procedures and documentation. The result of this process should be an organization that is prepared to work closely with another organization (McGeorge and Palmer, 1997).

\section{Development of Relationship-Based Procurement (RBP) methods in Australia}

The Australian construction industry suffered in the same way as the industry did in other parts of the world. National Public Works Conference and National Building and Construction Council Joint Working Party (1990) indicated that during the late 1980's, the Australian building and construction industry had substantial increases in the incidence of contractual claims and disputes compared to the previous ten years (Kwok and Hampson, 1997). This trend continued with increasing disputation and litigation, and win-lose attitudes promoted increasingly with adversarial relationships among project team members. At last the Final Report of the Royal Commission into Productivity in Building Industry in New South Wales and Gyles (1992) clearly indicated the need for a change; to a more cooperative approach to build mutual trust, respect and good faith to overcome the emerging environment of litigation within the industry.

Relationship-based approaches to project contracting have arisen in response to the above stated problems (Manley, 2002). Alliancing and Early Contractor Involvement (ECI) are two key forms of relationship-based approaches employed on construction projects (Walker, Hampson and Peter, 2000). Both methods subscribe to the concept of partnering which was introduced to Australia during the 1990s as a technique for managing cultural environments of projects that can be applied to other procurement forms (Masterman, 2002; Walker and Lloyd-Walker, 2014). Project-based partnering was developed by Charles Cowan in the US context in the early 1990s and has subsequently been adopted in Australian road projects.

Originating in the UK, Alliances first appeared in Australia in the 1990s when the oil and gas industry began to use "project alliances" in the development of energy projects during the mid1990s. Three major projects in Western Australia, namely Wandoo oil, East Spar gas field and Port Hedland iron ore were procured under the project alliance method. Since then, many projects have been procured by alliancing including Roxby Downs metal ore in South Australia, North side Storage Tunnel project in NSW; the National Museum and Institute for Aboriginal and Torres Strait Islander Studies on the Acton Peninsula in the ACT, and a new waste water treatment plant at Woodman Point, south of Perth in WA (Abrahams and Cullen, 1998). Within the Australian public sector there are different types of legal/commercial relationships in use that are referred to as "alliances"; for the Australian public sector the term refers to a specific means of project delivery or 'procurement option' where the principal and contractor work together collaboratively in an effort to deliver outcomes of a project in a no blame/no-disputes environment with a shared risk mechanism (Davies, 2008).

Early Contractor Involvement (ECI) is another relationship based procurement method that strives to involve the contractor at the early stage of the project, normally soon after the feasibility planning approval process has been completed. The concept of early involvement of contractors, however, is not new and can be traced back to pre-industrial revolution times when master artisans worked with a client commissioned agent to build large-scale structures. The term was formally acknowledged in the industry during 1990s when the concept of buildability drew academics and participant interests including the Construction Industry Institute in the US (CII) and its counterpart in Australia (CIIA) (Walker and Lloyd-Walker, 2014). According to 
Alliancing Association of Australasia (2008), ECI contracting is a process where the designer and constructor work together in a contractual relationship with the client, firstly to scope and price a project and then to design and construct a project. In this two-stage procurement and contractual model, the client appoints design and construction professionals early in the project development process through a non-price based selection, on the basis of the contractor's track record and availability, understanding of the project and quality of new ideas (Laursen and Myers, 2009), and those professionals assist in planning, assessing buildability and developing an "open book" target cost in conjunction with the client. The target cost is agreed before construction, and detailed arrangements for the distribution of potential extra costs or savings are determined (Mosey, 2009).

\section{Research method}

This research focuses on the clients who were involved in a RBP scheme. Grounded Theory methodology was used in this study as it was found an appropriate qualitative method for answering the research question. Subsequent to an initial review of the literature it was decided that the concept of RBP was still new knowledge in the construction industry and there is a dearth of research in this area. On account of the novelty of RBP, grounded theory could provide an efficient means of generating new conceptual categories and illustrating the current situation. In order to identify the core categories, the analysis process adopted a 'thematic analysis' approach for the identification of common threads that extends throughout an entire interview or set of interviews. The process was also guided by the 'constant comparison' of participants' responses considered as one of the core Grounded Theory analytical tenets highlighted by Suddaby (2006). Finally, all findings were integrated and collated to produce discussion and the subsequent conclusion.

The strategy for recruitment of participants for this study was driven by the principles of 'purposive sampling' advocated by Corbin and Strauss (1998). The purposive sampling strategy seeks involvement of participants who could contribute to the generation of the concepts being explored. Targeted participants were involved in the construction industry within Australia and those who were involved in a RBP scheme.

Since RBPs have been mainly adopted for infrastructure projects in Australia, the infrastructure departments of state governments were selected as the targeted samples. All the departments had utilized a type of RBP as well as other traditional procurement methods for their completed infrastructure projects, or those projects in progress at the time of research. According to Gibb and Isack (2001) the regulated infrastructure clients are more knowledgeable about the construction process and standard components than other private or public clients. There are six states in Australia with their own state constitution dividing the state's government into the same divisions of legislature, executive, and judiciary as the federal government (Australian Government, 2015). Approval to conduct the study within the organization was sought from senior executives of each state through emails (in total six requests sent). Four departments responded to the request and agreed to participate in the research project. Upon receipt of the approval, a list of candidates who had interest in participating in the research study, including their contact details, was requested. Initial participants were sought through invitational emails sent directly to them or their secretary. As the study continued, additional participants were identified through a 'snowball sampling' approach. In addition, one leading professional consultant organization, specialist in the establishment and delivery of collaborative contracts for complex projects and programs, was also selected to moderate the possibility of biased perception of the clients toward the use of RBP. All interviewees were in senior leadership roles within their department with several decades of experience within their field of practice and could provide input regarding their experience in that area. 
Since the analytical process of grounded theory aims to achieve theoretical saturation - a state after which no more data makes any useful contribution, grounded theory methodology doesn't impose any limit on the number of people to be interviewed in the research process (Maqsood, 2006).

The analysis process in this study adopted a 'content analysis' approach for the identification of common threads that extends throughout an entire interview or set of interviews. The process was also guided by the 'constant comparison' of participants' responses considered one of the core Grounded Theory analytical tenets highlighted by Suddaby (2006) in order to attain theoretical saturation of the concepts under exploration.

The analysis reached theoretical saturation after fourteen individuals who had been involved directly in managing a RBP were interviewed. This sample could perfectly represent all four infrastructure departments of each state's government in Australia and the private professional consultant organization.

Semi-structured in-depth interviews with fourteen senior managers and key players of the organizations were conducted within three months in 2014. Six individual interviews with respondents within organization 1; four individual interviews with respondents within organization 2; one individual telephone interviews with respondents within organization 3; one individual telephone interviews with respondents within organization 4; and two individual interviews with respondents within organization 5 were conducted. An overview of the interview participants' details is provided in Appendix 1. Using in-depth interviewing technique enabled detailed discussion of the issues tackled in the research. Each participant was asked a series of questions relating to their perspectives on the RBP method utilized recently, their overall assessment of the project outcomes as a result of the adopted RBP method, and the possibility of using a RBP method for the similar type of projects in the future. Each interview took approximately one hour, was recorded and then transcribed. This yielded approximately 300 transcription pages. The analysis process was carried out with the use of the latest version of qualitative data analysis toolkits, QSR-NVivo10.0.303.0, to organize and assist with the analysis of contents from interviews.

\section{Validity and consistency}

Validity and consistency of the findings were ensured by closely following the strategies prescribed by Merriam (1995) to strengthen internal validity, reliability and external validity.

The notion of internal validity of the research was addressed as below:

Theoretical triangulation: practicing theoretical coding procedures as close as possible to the analytical coding procedure described by Strauss and Corbin (1990) and confirming the findings with the substantive literature.

Member check: transcription derived from the audio recorded interviews was sent back to the interview respondent from whom the data was gathered, to check and confirm that the transcription was accurate and plausible.

Peer/Colleague examination: findings of this study were constantly checked and examined by experienced internal and external researchers.

Statement of researcher biases: every effort was made to explain the whole process of the research study and present the researcher's experience, assumptions and biases towards collecting, interpreting and developing the results. 
Engagement in the research situation: the duration of each individual interview was long enough to ensure that all interview questions were sufficiently answered and discussed by participants and an in-depth understanding of the phenomenon had been attained.

In the social science in which people and human behaviors are involved, measurements and observations can be repeatedly wrong, hence the whole notion of reliability in and of itself is problematic (Merriam, 1995). Lincoln and Guba (1985) pointed out that in qualitative studies the question is not whether the results of one study are the same as the results of a second or third study. Instead the qualitative researchers need to demonstrate that the results of a study are consistent with the data collected.

In an effort to ensure for greater consistency of this study, some of the strategies used for internal validity could be employed as suggested by Merriam (1995) i.e. triangulation and peer examination. Beside those, the process as to how the data was collected, how categories were derived and how decisions were made throughout the study (Merriam, 1998) was described in detail in preparation for this research. The soundness of the results was then confirmed by the interview participants.

Strategies adopted to ensure the external validity of this study are highlighted below:

Thick description: detailed description of the research process throughout all phases was provided, enabling readers to determine how this research closely matched their situation and whether the findings are transferable (Merriam, 1995). The details towards the conceptualization and formulation of the results also enable other researchers with any perspectives to follow the analysis process, to understand the analytical logics, and confirm the plausibility of the explanation of the phenomenon (Corbin and Strauss, 1998)

Multi-site design: this study used 14 experts from 4 different client organizations within different states in Australia and one professional consultant organization located in Victoria in attempt to allow the results to be applied to a greater range of other similar situations (Glaser and Strauss, 1967).

\section{Results}

The participants interviewed had different perception toward their experience of using a RBP method for their projects. Responses varied from utterly positive with outstanding outcomes, to very negative with a great regret at not using a traditional method instead. There were also a range of responses indicating mixed success with a RBP method. For example, one participant commented that 'we had some very successful projects by using a relationship-based contract. It enabled us to reform the initial relationship with the contractor and build a more cooperative type of relationship leading to an outstanding success' (P8). Another response that implied a mixed success was 'we have had some very good successes and a couple that have not gone as well as we would have liked' (P10). There were also negative comments such as 'there were a couple of RBP for rail electrification that they haven't delivered on time and we have been pretty disappointed in the results. The critical question mark was that perhaps we could have gotten a better outcome if we had just gone into a competitive tender' (P7). From the analysis, particular issues were identified that clearly caused clients to become cynical about using a RBP. Key themes emerging from the clients interviews are summarized below:

\section{Lack of competition}

RBPs were criticized by clients as impeding the demonstration of value for money, especially when ,accountability for public expenditure is required to be manifested to the government. Even though clients admittedly indicated that the competition would undermine the quality of 
the working relationship with contractors, lack of competition inherent in the RBP characteristics was reported as being more problematic due to inability of clients to attain a benchmark for comparing the value of delivering the project under a RBP with a lump sum Design and Construct (D\&C) with that of Design-Bid and Build (DBB). Commenting on this, participant P9 explained that '... RBPs are a bit of, or potentially, a bit of a softer price. So, you don't have the hard competitive edge that you would in a traditional contracting sense of D\&C or construct-only types. Our challenge was to ensure that there was a Value for Money outcome, that it was going to give us what we expected in terms of scope, and then once we agreed on price, we had to go to the Cabinet to get approval to award the contract.'

In addition, some of the respondents argued that innovation is driven by competition. Contrary to the general perception that RPBs facilitate innovation, lack of competition was seen as an impediment to obtaining innovative ideas by contractor. Innovation can be seen as a competitive advantage of the opponents to win the contract in a competitive environment, however when one contractor is appointed with no competition, the necessity to push the limits is eased and the sole contractor prefers having design and/or delivery of the project go along as usual. One participant indicated that '...my honest opinion is that competition drives innovation and if you've got no competition, contractors will want a business as usual approach for that and I don't think they'll actually push the boundaries because they'll think, once they're on board, we will do what we normally do and this is what it will cost.' (P7)

\section{Misinterpretation of the relationship}

Clients believed that some contractors did not understand the principles of RBPs properly in that a relationship framework did not override the requirements of the contract. Contractors often misinterpreted what the contract required and they perceived the relational contracting as an opportunity to avoid or work around the contract by using the relationship instead of being aware that the relationship was there just to help to smooth the contract. In some instances, this misinterpretation engendered destruction to the working relationship between the client and contractor as a result of not respecting the hierarchy of the communication that had been defined in the contract. The participant P4 argued that'...certainly there is a lot of confusion, not a lot but typically our problems deteriorate on our RBP projects when people do not understand that whilst we have a relationship framework, it does not override the requirements of the contract, so they misinterpret what the contract requires and they think that they can neglect or disregard the contract by using the relationship that we have. It is a big challenge to make everyone in the project understands that the relationship is to facilitate how we should work the contract out'.

\section{Resource hungry}

The need for involvement of high level management teams from client's side throughout the project was reported as another challenge clients have encountered. On top of the design teams, clients had to add their internal designers also as the custodian of the standards, to answer the potential questions and provide advices. They had to acquire trained persons for the administration of the process, ensuring the whole process was progressing as per the plan and that teams were operating efficiently. Respondents described the instances in which resources were tight and providing enough internal expertise was a big challenge that they had to deal with. Participant P2 explained that '....we're tying up three contractor and designer teams for the period of several months. We also have to add our internal resources on top to sort of feed that process as well, so we generally have an embedded designer in each team and they're effectively full-time with that project team. We have to have our people also so we can contact our engineering and technology branch, to make sure the process is in line with standards. We have to have the right 
people there on top to respond to the team inquiries and guide them accordingly. We've got to have skilled experts to govern the process and direct the teams...bringing all the available resources all along the journey to support the delivery teams is very difficult'. However, the use of some RBP alternatives such as ECI, in which elements of traditional contracts could be traced, was the solution to some extent.

\section{Cultural barriers}

Culture of organization is viewed as one of the key factors in successful implementation of a RBP. The need for substantial changes in the organizational culture was identified as being a reason for clients becoming reluctant to adopt RBP for their projects. The culture of partnering requires different sorts of personalities and attitudes of key players towards the project parties. On one hand, clients are not able to discard the experienced managers, since their skills and knowledge are crucial to delivery of the project, yet on the other hand, experienced managers have a completely different mindset towards working relationships as they have grown up in an environment that is adversarial or always has been adversarial. They find it difficult to transition into more of a relationship type of environment. Participant P3 stated that 'The problem is that staffs around the place get different ideas from different methodologies. They all bring different experiences to the table. Contractors are the same. I see this all the time. I'm actually seeing it on a project at the moment. If the contractors have traditionally worked in client-led design system, they have certain perceptions. If they've worked in a hard-dollar D\&C or an Alliance, they once again have different perceptions. So, if you want to facilitate or run a RBP, it needs to be championed by someone who knows what they're doing. That's the catch'.

\section{Unsuitability of the project}

Project procurement choice is influenced by a number of factors. Size and complexity of a project were identified as being important determinants for clients adopting RBP. Normally, large projects with a high degree of complexity are more suited to RBP as the upfront costs of the project should be justified by the potential gains through using RBP. In addition, the pain/gain share mechanism as the underlying principle of RBP compensation regime is justifiable only if the cost of risk eventuation associated with the project is more, or equal to, the extra money the contractor would earn if the risks are managed jointly. Therefore, it is generally accepted that small and straight forward projects can be better managed and delivered by conventional procurement methods. '... as an average statement I would say a simpler project would not need so much design work done, whereas as a more complex project you might need to take the design forward; you might need to go well beyond concept design; you might need to go as far as fully design stage to get good value or best value by collaborating with the contractor. So, I suppose I'm resting on the issue of project complexity, or perhaps more appropriately the degree of uncertainty in the project when considering RBP for the project' (P14). However, clients admitted that ,choice of RBP in many instances was not based on the factors pertaining to the project characteristics. Rather, some other factors such as political or the market situation influenced the decisions in favor of selecting RBP system. A senior contract manager of one of the organizations for instance said '.. to select RBP for a project, we will look at the characteristics of the existing industry at the time, or the market availability at the time. We would look at the market or the industry's capability and availability. If you've got a highly competitive marketplace you could argue RBPs may not deliver as much value.' (P1). Or a general manager of another organization who was involved in major transportation projects emphasized that ' $\ldots$ it is sometimes basically dictated by certain factors which cannot be controlled, such as political environment, the community related things, which can force you go 
into one direction, from the other. So in choosing a RBP they are also part of the influencing parameters'. (P6).

Clients also explained that in some instances, RBP was used as a trial to experiment with new methods of procurement in an effort to understand the process and learn the differences with the other procurement options. A project director at the infrastructure delivery directorate pointed out that 'The RBP that we did was more or less a bit of a trial. It worked reasonably well, but we haven't done another one since. Maybe that's an indication of where we're at, that maybe things are better done as a D\&C, RBPs don't really apply all that often'(P11).

\section{Discussion}

The central tenet of using a relationship based procurement method is that the collaborative relationship between parties can address the inefficiency of the construction industry (Egan, 1998; Latham, 1994). In recent years there has been a growing interest in the use of these procurement systems in the construction industry. However, despite the industry reports a large number of successful projects delivered under a relationship based procurement method, the use of these strategies is being placed under scrutiny and there is still considerable disagreement about the actual value they can add to the projects (Barlow et al. 1997; Bresnen and Marshall, 2000; Thompson and Sanders, 1998). The findings of this study have suggested that clients consider the use of these strategies with extra care. One of the challenges for the pure relational methods such as alliances, is responding to the need to demonstrate value for money. Since governments utilize relational contracting for major public projects, exploring and testing the value for money proposition are the key factors that will determine the use of these strategies in the future. Nevertheless, these models remain unproven for a number of authorities in government departments who influence the procurement decisions for projects (Walker and Lloyd-Walker, 2014). Relationship-based procurement approaches have been unable to demonstrate the full value of what they have done and it probably does not make sense from an accounting point of view, since they look more expensive than traditional delivery models. However the concern regarding value for money can, in part, be addressed by the transparency that arises from the usual audit processes put in place for the project (Greenham, 2007).

Another challenge in using relational contracting suggested by practitioners, is the contractors' misunderstanding of the working relationships and the contractual requirements. Fundamental change in the perception of contractor toward the contractual obligations is required when the working relationship with the client is characterized as collaborative. While implication of a formal contract is insufficient to ensure effective working relationship between client and contractor (Merrow, 2011), the existence of a formal contract is essential to govern the entire project delivery process. This finding supports the prior finding by Suprapto et al. (2015) that a formal contract is important to structure the clarity of roles and responsibilities among parties, although relatively less influential on the working relationships. Contractors therefore need to refrain from exploiting the soft aspect of a relational contract in favor of their own benefits. Instead, the relationship with the client should be perceived as an opportunity to facilitate the delivery of project under governance of the contract.

Notably the client's internal environment has a significant influence on the decision whether or not a relationship-based procurement strategy should be adopted. Two main aspects of the internal environment that identified as barrier or driver of using such strategies are the in-house resource availability and the working culture of key players. While the involvement of high-level management is essential in relationship based procurement methods (Ross, 2003), in some instances clients experienced difficulty in allocating adequate numbers of people into the project as a result of either the staff shortage or the lack of alignment between an individual's culture and orientation with the principles of the RBP culture (Morwood et al., 2008). 
Finally, the findings have suggested that clients are becoming more mature in the selection of RBPs for projects as a result of learning from previous projects. This greater maturity has caused a reduction in the popularity of RBPs as clients carefully evaluate the suitability of the project to be procured under RBP rather than using it as a leap of faith. This proposes that despite the possibility of a decline in the rate of using RBP for public projects, the number of RBP projects with higher success is more likely to increase.

\section{Conclusion}

This paper provided the historical development of procurement briefly and then focused on the adoption of Relationship-Based Procurement (RBP) approaches in the Australian construction industry, to investigate the future direction of collaborative project procurement arrangements. The use of collaborative procurement methods in the past few decades has been significantly increased and Australia is one of the pioneers in the utilization of Alliancing and ECI that can be defined as the purest relationship-based procurement systems. This study has identified some significant factors that negatively affect client use of relationship based procurement methods. It has shown that despite appreciation of collaborative procurement methods by those who have been involved directly in such models, issues such as inability of these methods to fully demonstrate value for money, cultural misalignment of senior managers with RBPs underlying culture, and the demand to engage senior level resources throughout the project, are the main reasons for a trend away from utilizing RBPs. However the industry appears to be more mature in adopting RBP for projects and making more informed decisions due to learning from previous project outcomes, to ensure the right project is procured under a collaborative method.

\section{References}

Abrahams, A. and Cullen, A., 1998. Project alliance in the construction industry. Australian Construction Law Newsletter, 62, pp.31-36.

Alliancing Association of Australia-AAA 2008. Report on Project Alliancing activities in Australasia 2008, The Alliancing Association of Australasia Limited, Australia

Australian Government, 2015. State and Territory Government. [online] Available at: http://www.australia.gov.au/about-government/how-government-works/state-and-territory-government [Accessed 8 Oct 2013].

Barlow, J. 2000. Innovation and learning in complex offshore construction projects. Research Policy, Vol. 29 (7) , pp.973-989. doi: http://dx.doi.org/10.1016/S0048-7333(00)00115-3

Bresnen, M., and Marshall, N. 2000. Motivation, commitment and the use of incentives in partnerships and alliances. Construction Management and Economics, Vol 18(5), PP. 587-598

Construction Industry Institute, 1991. In search of partnering excellence. Bureau of Engineering Research. Austin, TX: University of Texas.

Corbin, J. and Strauss, A., 1998. Basics of qualitative research: Techniques and procedures for developing grounded theory. $2 \mathrm{nd}$ ed. Thousand Oaks: Sage Publications.

Davies, J.P., 2008. Alliance contracts and public sector governance. PhD. Griffith University. Available at: https://www120.secure.griffith.edu.au/rch/file/f290d391-d099-2ad1-4a01-814daf88434d/1/02Whole.pdf

Egan, J., 1998. Rethinking construction. London: Department of Trade and Industry.

Gibb, A.G. and Isack, F., 2001. Client drivers for construction projects: implications for standardization. Engineering Construction and Architectural Management, 8(1), pp.46-58. Available at: http://onlinelibrary.wiley.com/doi/10.1046/j.1365-232x.2001.00184.x/pdf and doi: http://dx.doi.org/10.1108/eb021169

Glaser, B.G. and Strauss, A.L., 1967. The discovery of grounded theory: Strategies for qualitative research. New Brunswick: Aldine de Gruyter.

Greenham, P., 2007. Alliancing: a glimpse of the real world view. Minter Ellison Lawyers, Melbourne.

Hinks, J., Cooper, R., Allen, S. and Carmichael, S. 1996. Is partnering a state of mind? A comparison of manufacturing and construction, in ESRC/EPSRC Workshop on Partnering in Construction, University of Salford, 13 May.

Kwok, T. and Hampson, K., 1997. Strategic alliances between contractors and subcontractors: a tender evaluation criterion for the public works sector. In: Construction process re-engineering: proceedings of the International Conference on 
Construction Process Re-engineering. Gold Coast, Australia, 14-15 July $2007 . \quad$ Available at: http://eprints.qut.edu.au/30067/1/30067.pdf

Laursen, T., and Myers, B. 2009. Public investment management in the new EU member states: strengthening planning and implementation of transport infrastructure investments, World Bank Publications, Vol.161. doi: http://dx.doi.org/10.1596/978-0-8213-7894-6

Latham, M., 1994. Constructing the Team. Final Report of the Government/Industry Review of Procurement and Contractual Arrangements in the UK Construction Industry. London: HMSO. Available at: http:/ / constructingexcellence.org.uk/wp-content/uploads/2014/10/Constructing-the-team-The-Latham-

Report.pdf http://www.greenspecdownload.co.uk/files/6013/9987/6664/Latham-ReportConstructing-the-Team.pdf

Lenard, D. and Mohsini, R. 1998. Recommendations from the Organisational Workshop, CIB W-92 Procurement The Way Forward, The University of Montreal, 18-22 May Davidson C. H. and T. A. Meguid, CIB, 1: 79-81.

Lincoln, Y.S. and Guba, E.G., 1985. Naturalistic Inquiry. Thousand Oaks: Sage Publications.

Love, P.E.D., Davis, P., Baccarini, D., Wilson, G. and Lopez, R., 2008. Procurement selection in the public sector: a tale of two states. In: Clients Driving Innovation: proceedings of Benefiting from Innovation Conference. Gold Coast, Australia 12-14 March 2008. Available at: http://eprints.qut.edu.au/27175/

Love, P.E.D., Edward, D.J., Irani, Z. and Sharif, A., 2012. Participatory Action Research Approach to Public Sector Procurement Selection. Journal of Construction Engineering and Management, ASCE, 138(3), pp.311-22. Available at: doi: http://dx.doi.org/10.1061/(ASCE)CO.1943-7862.0000440

Love, P., Skitmore, M. and Earl, G., 1998. Selecting a suitable procurement method for a building project. Construction Management and Economics, 16(2), pp.221-33. Available at: doi: http://dx.doi.org/10.1080/014461998372501

Love, P., Smith, J. and Regan, M., 2010a. Comparative procurement methodology analysis in Australia: A new approach. Proceedings of W092-Special Track 18th CIB World Building Congress. Salford, United Kingdom, May 2010 p.37. Available at: http://www.irbnet.de/daten/iconda/CIB DC24228.pdf\#page $=45$

Love, P., Smith, J. and Regan, M. 2010b. Procurement Method Selection in Practice: A Journal to Discover the Optimal. In CIB World Congress 2010: Building a Better World, May 10, 2010, Salford Quays, Manchester, UK: The University of Salford, School of Built Environment, Maxwell Building, Salford, UK.

Maqsood, T., 2006. The Role of Knowledge Management in Supporting Innovation and Learning in Construction. PhD theses. RMIT University. Available at: https://researchbank.rmit.edu.au/eserv/rmit:6223/Maqsood.pdf

Manley, K., 2002. Partnering and Alliancing on road projects in Australia and Internationally. Road and Transport Research, 11(3), pp.46-60. Available at: http:/ / eprints.qut.edu.au/7286/

Masterman, J.W.E., 2002. An Introduction to Building Procurement System. 2nd ed. London: Spon Press.,

McDermott, P., 1999. Strategic and emergent issues in construction procurement. In: Rowlinson, S. and McDermott, P.E., eds., Procurement Systems: A Guide to Best Practice in Construction. London: F. Spon. pp.3-26.

McDermott, P. and Khalfan, M.M.A., 2006. Achieving supply chain integration within construction industry. The Australian Journal of Construction Economics and Building, 6(2), pp.44-5. Available at: doi: http://dx.doi.org/10.5130/ajceb.v6i2.2983

McGeorge, D. and Palmer, A. 1997. Construction Management: New Directions, Blackwell, Oxford.

Merriam, S., 1995. What Can You Tell From An N of 1?: Issues of Validity and Reliability in Qualitative Research. PAACE Journal of Lifelong Learning, 4(1995), pp.51-60. Available at: https://www.iup.edu/WorkArea/DownloadAsset.aspx?id=18193

Merriam, S.B., 1998. Qualitative Research and Case Study Applications in Education. Revised and Expanded from "Case Study Research in Education". San Fransisco: Jossey-Bass Publishers. Available at: ERIC http://eric.ed.gov/?id=ed415771

Merrow, E.W., 2011. Industrial megaprojects: concepts, strategies, and practices for success. New York: John Wiley \& Sons.

Miller, G., Furneaux, C., Davis, P., Love, P. and O'Donnell, A., 2009. Built Environment Procurement Practice: Impediments to Innovation and Opportunities for Changes. Perth: Curtin University of Technology.

Mohsini, R., and Davidson, C.H., 1989. Building Procurement - Key to Improved Performance. In Cheetham, D., Carter, D., Lewis, T., and Jaggar, D.M., Contractual Procedures for Building: Proceedings of the International Workshop, 6-7, April, University of Liverpool.

Morledge, R., Smith, A. and Kashiwagi, D.T., 2006. Building Procurement. Oxford: Blackwell Publishing Ltd.

Morwood, R., Scott, D., Pitcher, I. and AECOM. 2008. Alliancing: a participant's guide: real life experiences for constructors, designers, facilitators and clients. Brisbane: Maunsell AECOM.

Mosey, D. 2009, Early contractor involvement in building procurement: contracts, partnering and project management, WileyBlackwell.

NPWC/NBCC Joint Working Party and National Public Works Conference (Australia) and National Building and Construction Council (Australia), 1990. No Dispute: Strategies for Improvement in the Australian Building and Construction Industry: report by NPWC/NBCC Joint Working Party. National Public Works Conference Dickson, ACT. Available from http://catalogue.nla.gov.au/Record/1827786 
Nissen, M.E. 2009. Procurement: Process Overview and Emerging Project Management Techniques. In: Morris, P. and Pinto, J.K. eds., The Wiley Guide to Project Technology, Supply chain, and Procurement management. Hanboken: Wiley. Chapter 11.

Palaneeswaran, E., Kumaraswamy, M. and Ng, T., 2003. Targeting Optimum Value in Public Sector projects through 'best value' - focused contractor selection. Engineering, Construction and Architectural Management, 10(6), pp.418-31. Available at: doi: http://dx.doi.org/10.1108/09699980310509390

Ross, J., 2003. Introduction to project alliancing. Project Control International Pty Limited (PCI group). Available at: www.pcigroup.com.au/publications pci/

Rowlinson, S. and McDermott, P., 1999. Procurement System: A Guide to Best Practice. London: Spon Press.

Royal Commission into Productivity in the Building Industry in New South Wales and Gyles, R.V., 1938-1992. Final Report. The Commission, Sydney.

Seymour, D.E. and Fellows, R.F. 1999. Towards a Culture of Quality in the Construction Industry, in Ogunlana, S. O. Profitable Partnering in Construction Procurement. London: E\&FN Spon, pp. 511-521.

Skitmore, R. and Marsden, D., 1988. Which procurement system? Towards a universal procurement selection technique. Construction Management and Economics, 6(1), pp.71-89. Available at: doi: http://www.tandfonline.com/doi/abs/10.1080/01446198800000008

Stevens, D., 1993. Partnering and Value Management. The Australian Institute of Quantity Surveyors Journal, The Building Economist, September, 5-7.

Strauss, A. and Corbin, J.M., 1990. Basics of qualitative research: Grounded theory procedures and techniques. Thousand Oaks: Sage Publications Inc.

Suprapto, M., Bakker, H.L., Mooi, H.G. and Moree, W., 2015. Sorting out the essence of owner-contractor collaboration in capital project delivery. International Journal of Project Management, 33(3), pp.664-83. Available at: http://www.sciencedirect.com/science/article/pii/S026378631400091X. and doi: http://dx.doi.org/10.1016/j.ijproman.2014.05.001

Suddaby, R., 2006. From the editors: What grounded theory is not. Academy of management journal, 49(4), pp.633-42. Available http://www.researchgate.net/publication/253203051 From the Editors What Grounded Theory Is Not

Thompson, P.J. and Sanders, S.R., 1998. Peer-reviewed paper: partnering continuum. Journal of Management in Engineering, 14(5), pp.73-8. Available at: http://ascelibrary.org/doi/abs/10.1061/\%28ASCE\%290742597X\%281998\%2914:5\%2873\%29. doi: http://dx.doi.org/10.1061/(ASCE)0742-597X(1998)14:5(73)

Walker, D.H.T., Hampson, K.D. and Peter, R.J., 2000. Relationship-based procurement strategies for the 21 st century. Canberra: Ausinfo.

Walker, D.H.T. and Lloyd-Walker, B., 2014. Collaborative Project Procurement Arrangements. Newtown Square, PA: Project Management Institute.

Wood ,G., 2005. Partnering practice in the relationship between clients and main contractors. RICS Research paper series, March 2005, 5(2). Available at: http://usir.salford.ac.uk/510/ 
Appendix 1: Details of interviewees

\begin{tabular}{|c|c|c|c|}
\hline Ref & Department & Role & Notes and Comments \\
\hline P1 & $\begin{array}{l}\text { State Program Office-Program } \\
\text { Delivery and Operations }\end{array}$ & $\begin{array}{l}\text { Director of Programs and } \\
\text { Specialist Delivery }\end{array}$ & $\begin{array}{l}\text { Involved in delivery of projects, mainly } \\
\text { transport industry, for about } 30 \text { years }\end{array}$ \\
\hline $\mathbf{P} 2$ & $\begin{array}{l}\text { State Program Office-Program } \\
\text { Delivery And Operations }\end{array}$ & Director of Program Services & $\begin{array}{l}\text { Working for over } 25 \text { years including delivering } \\
\text { marine projects and major road projects }\end{array}$ \\
\hline P3 & $\begin{array}{l}\text { State Program Office-Program } \\
\text { Delivery And Operations }\end{array}$ & $\begin{array}{l}\text { Assistant Director in Infrastructure } \\
\text { Management and Delivery }\end{array}$ & $\begin{array}{l}\text { Worked in construction for over } 30 \text { years mainly } \\
\text { for major infrastructure projects }\end{array}$ \\
\hline P4 & $\begin{array}{l}\text { State Program Office-Program } \\
\text { Delivery And Operations }\end{array}$ & Construction Team Leader & $\begin{array}{l}\text { Worked for the department for more than } 20 \\
\text { years and performed mostly consulting role with } \\
\text { designers and contract administrators. }\end{array}$ \\
\hline P5 & $\begin{array}{l}\text { North District Office in } \\
\text { Program Delivery and } \\
\text { Operations Branch of the } \\
\text { Department }\end{array}$ & Principal Engineer (Civil) & $\begin{array}{l}\text { Working over } 40 \text { years mainly in road } \\
\text { construction looking after contracts and } \\
\text { building major infrastructure }\end{array}$ \\
\hline P6 & $\begin{array}{l}\text { State Program Office-Program } \\
\text { Delivery And Operations }\end{array}$ & General Manager & $\begin{array}{l}\text { Working for more than } 20 \text { years in traffic and } \\
\text { transportation. }\end{array}$ \\
\hline P7 & Contracting Services & General Manager & $\begin{array}{l}\text { Working in the department for } 33 \text { years and has } \\
\text { worked for various Design and Construct } \\
\text { sections }\end{array}$ \\
\hline P8 & $\begin{array}{l}\text { Rail at Public Transport } \\
\text { Services }\end{array}$ & Senior Contract Manager & $\begin{array}{l}\text { Working for } 16 \text { years in civil engineering and } \\
\text { performed as a contract manager within the } \\
\text { department }\end{array}$ \\
\hline P9 & Rail Revitalization Program & Project Director & $\begin{array}{l}\text { Worked in the major capital projects delivery } \\
\text { area for } 16 \text { years including revitalization of the } \\
\text { metro and suburban rail net way }\end{array}$ \\
\hline P10 & $\begin{array}{l}\text { Network Safeguard and } \\
\text { Development }\end{array}$ & General Manager & $\begin{array}{l}\text { Working for more than } 20 \text { years for the } \\
\text { department in the contract management and } \\
\text { project management }\end{array}$ \\
\hline P11 & $\begin{array}{l}\text { Infrastructure Delivery } \\
\text { Directorate }\end{array}$ & Project Director & $\begin{array}{l}\text { Worked for the department for about } 20 \text { years } \\
\text { and been involved in a number of major road } \\
\text { works contracts including Alliance-type } \\
\text { contracts and an ECI contract }\end{array}$ \\
\hline P12 & Department of major projects & Project Manager & $\begin{array}{l}\text { Working for more than } 20 \text { years for the } \\
\text { department including large contracts projects }\end{array}$ \\
\hline P13 & Specialist consultant & Founder of the organization & Over 30 year experience in RBP methods \\
\hline P14 & Specialist consultant & Senior Consultant and Partner & Worked in management consulting for 30 years. \\
\hline
\end{tabular}

